\title{
Treatments of produced water in oilfield: A comprehensive review
}

\author{
Lingyun Chen $^{1 *}$, Zhigang $\mathrm{Li}^{2}$, and Qian $\mathrm{Liu}^{3}$ \\ ${ }^{1}$ Key Laboratory of Enhanced Oil Recovery (Northeast Petroleum University), Ministry of Education, \\ Daqing, China \\ ${ }^{2}$ Northeast Petroleum University, School of Physics and Electronic Engineering, Daqing, China \\ ${ }^{3}$ Daqing Oilfield, Engineering Team of 2nd oil Production Plant, Daqing, China
}

\begin{abstract}
Substantial produced water in oilfield need to be treated. Treatment mechanism such as adsorption, flotation, filtration, desalination, etc. are described. Based on the mechanisms, process and technology, tools and facility for produced water treatment are compared. Technology selection method and requirements are discussed. Multiple processes combination is discussed and considered as promising.
\end{abstract}

\section{Introduction}

When an oil field matures, it produces more produced water than before. Steam flooding heavy oil-bitumen can generate water 2 to 20 times as much as oil, approximately four in most cases. Hence, the volume of produced water generated in the cases can be substantial. Although much of the produced water in oilfield may either be unspoiled or reused in the following recovery, most oilfield production generate huge amount of polluted waters need to be safely discharged.

There are a few factors to consider for proper treatment levels and technologies, such as disposal methods, goals, environmental impacts, and economics.

At some locations, produced water contains substantial total dissolved solids, which is unsuitable for reuse in oilfield unless treated, reduce dissolved solids concentrations and reach standard level.

For characterization and treatment of produced water, technologies evaluation, literatures are reviewed to identify reasonable ones, considering technical and economic influence.

\section{Process and Technology for treatment}

\subsection{Adsorption treatment}

The produced-water at a crude-oil gathering facility was mixture of brine and oil from different reservoirs, with complex and changing ingredients. Flotation, filtration, and

\footnotetext{
*Corresponding author: 462415985@qq.com
} 
adsorption trials ${ }^{1}$ are conducted. Different coagulant, Inlet-dispersed oil-in-water concentrations, and Turbidity are used in Induced-gas-flotation.

Dispersed oils were removed by coagulation/flocculation and flotation. The lower PAC addition resulted in higher dispersed-oil concentration reduction in water treated. Flotation reduced Turbidity, and Filtration further reduced it at greater rates, by removing all suspended solids remained by flotation. Activated-carbon adsorption removed dissolved oil, thus it reduce OIW concentrations.

\subsection{Desalination or TDS removing}

Some researchers doubt the existing technologies as the best choice about incorporating selective ions and water management in situ reservoir. Seawater and produced water injection are recognized as suitable for injection-fluid chemistry alteration in carbonate reservoirs.

Traditional chemical-precipitation methods are feasible to remove some kinds of ions in seawater, for example, lime/soda ash, alkali, or lime/aluminium-based reagent. The third one remove sulfates and hardness ions from injection fluid.

As a better choice to reverse-osmosis seawater desalination, forward osmosis and membrane distillation is cost-less, heat or steam wasted less, based on dynamic vapor recompression and carrier-gas extraction, it's suitable for produced water salinity treatment and discharge no fluid, although still not an economic approach.

Three seawater-desalination methods may be promising in the future, i.e. carbon nanotube-based, graphene sheet-based, and capacitive deionization. Among the three technologies, the first one has more advantages in field application.

Through reviews and analysis, former researchers selected and combined chemical precipitation, conventional desalination, and produced-water-treatment methods to propose several conceptual processes for discussion.

Mechanical-vapor-recompression process ${ }^{2}$ can demineralize concentrated brines reliably. Caustic addition and clarification for total-suspended-solids and iron control are conducted. Then shale-gas flowback water flow to following parts.

Distillation recovery most of the influent water, and influent total dissolved solids are less than $50,000 \mathrm{mg} / \mathrm{L}$ on the average. From the distillation, removal most amount of iron, magnesium, calcium, barium, and boron, and benzene, toluene, ethylbenzene and xylenes.

Comparing economically and technically, evaporation, some experts regard membrane processes and freeze desalination as the most promising methods to remove total dissolved solids ${ }^{3}$. Vapour compression cost least.

\subsection{Phenols biodegradation in packed bed slime reactor}

The aromatic ring in organic phenols is confirmed not only very stable but also toxic, which make phenols hard for degrading naturally and dangerous.

A slime reactor with packed bed ${ }^{4}$ performs efficiently on phenols biodegradation, even better than aerated lagoon. Organic produced water in oilfield pilot flow through a packed column with high concentration bacteria hold inside, whose flowrate is faster than that of former reviews, and the phenols biodegradation is considered totally effective.

\subsection{Bioremediation for produced water in oilfield}

A novel technology 5 for produced water bioremediation in oilfield composed of an impermeable liner, a horizontal subsurface flow gravel bed reactor, and an oxygen delivery improving system. There are several parameters needed to adjust, such as flowrate, effluent 
concentrations required, and coefficients of biodegradation rate, hydraulic residence time, and influent. It may take the place of remediation processes in mechanical way.

\subsection{Chemical flocculation of suspended solids}

A suspended solids treatment ${ }^{6}$ based on chemical flocculation was evaluated. Hydraulicfracturing produced water with suspended solids are chemically flocculated with magnetite. After gravity separation, the drum-styled magnetics remove solids. The magnetic flux in the process resist the gravity forces, thus enhance separation efficiency.

\subsection{SAGD produced water treatment}

As a recovery method for heavy oil $^{7}$, SAGD produced massive waste water, which is stable compositional emulsion fluid. To destroy the highly stable state, it's crucial to break the stable structure of polycyclic aromatic hydrocarbons on the emulsion drop surface.

In the treatment of produced water for $\mathrm{SAGD}^{8}$ heavy oil recovery, nowadays people tend to choose falling film, mechanical vapour compression evaporation to produce steam generator feedwater, instead of warm lime softening, filtration and weak acid cation ion exchange to pre-treat produced water.

\section{Tools and facility for treatment}

\subsection{Air-sparged hydrocyclone}

It's hard to purify polymer-produced water in conventional gravity settling ways. After the treatment of double-cone air-sparged hydrocyclone ${ }^{9}$, much lower oil concentration of treated water is reached(less than $100 \mathrm{mg} / \mathrm{L}$ ), which is a relative higher separation efficiency than conventional methods. In the treatment facility, centrifugal force increase the energy between particle and bubble, which cause more film rupture, bubble attachment and flotation.

\subsection{Hydrophilic fibre ball medium for ASP produced water}

A kind of hydrophilic fibre ball medium ${ }^{10}$ was developed through surface modification. After injection of alkaline, surfactant and polymer solution, some chemicals remains in the ASP flooding produced water. Especially some kind of them could greatly decrease the W/O interfacial tension (IFT), which keep oil droplets stable, and fewer approach and coalescence.

\subsection{Cross Flow pack separator for oil/water separation}

To improve oil/water separation, a modified standard Cross Flow Pack ${ }^{11}$ separator shake its plate pack, which decrease the probability of plates plugging and make the separator much more effective than before.

The increment in effectiveness is because of plate pack shaking and its peak value at flow Reynolds number (where characteristic length: hydraulic diameter) is reached. Averagely, if it's O/W concentration was greater than 150 parts per million, the stream is removed all oil drops larger than 30 micron. 


\section{Technology Selection Discussion}

Not only dispersed hydrocarbons but also dissolved compounds and/or all toxicity in produced water are targeted in treatment. Consequently, treatments procedure needs higher efficiency, reliability of installations and compactness, especially offshore facility. Although biological process may compromise well with removal efficiency and economic evaluation, lack of compactness cause it unsuitable to implement at offshore field. Multiple processes combination, or hybrid processes, is considered more promising than conventional methods.

Adequate comparative assessment of technologies and selection of the best option for a particular oil field is essential. Choice of waste management technologies should be based on reliable data; therefore, it has to include information and analysis of drilling waste treatment technologies, legal restrictions, climatic and geological conditions of the territory, as well as information on field development program, existing and planned technologies and infrastructure.

A feasibility analysis of specific techniques for certain fields, a comparative technological and economic assessment for implementing appropriate technologies should be included.

The analysis puts forward a list of technologies that comply with legislation, meet the limitations of application, and other mandatory criteria. At the same time, technologies are excluded from further consideration that, despite possible advantages over other options (for example, low costs, high productivity, etc.), cannot be implemented in this field in principle. The economical assessment stage compares technical and economic indicators of different waste management options and selects the best technology. Thus, the proposed systematic approach to the integrated assessment of technologies by technological, environmental, economic, and other criteria generates a list of technologies, recommended for use at a specific facility, and ranks them.

\section{References}

1. Al-Maamari, Rashid S., Sueyoshi, Mark, Tasaki, Masaharu, Okamura, Kazuo, AlLawati, Yasmeen, Nabulsi, Randa, and Mundhir Al-Battashi. "Flotation, Filtration, and Adsorption: Pilot Trials for Oilfield Produced-Water Treatment." Oil \& Gas Fac 3 (2014): 56-66.

2. Hayes, Thomas D., Halldorson, Brent, Horner, Patrick H., Ewing, John Jay R., Werline, James R., and Blaine F. Severin. "Mechanical Vapor Recompression for the Treatment of Shale-Gas Flowback Water." Oil \& Gas Fac 3 (2014): 54-62.

3. Kok, S., Zaidi, A., and R. Solomon. "Total Dissolved Solids Removal From Water Produced During The In Situ Recovery Of Heavy Oil And Bitumen." J Can Pet Technol 28 (1989): No Pagination Specified.

4. Hill, G.A. "Packed Bed Slime Reactor: A New Technology for Petroleum Wastewater Purification." J Can Pet Technol 32 (1993): No Pagination Specified.

5. Wallace, Scott, and Brian M. Davis. "Engineered Wetland Design and Applications for On-Site Bioremediation of PHC Groundwater and Wastewater." SPE Proj Fac \& Const 4 (2009): 1-8.

6. Ringler, Eric, Chatterton, Bill, Philbrook, Dave, and Blaine F. Severin. "An Advanced Clarification Process for Treating Produced Waters." SPE Prod \& Oper 33 (2018): 154-163. 
7. Nasiri Masoud; Jafari Iman. "Produced Water from Oil-Gas Plants: A Short Review on Challenges and Opportunities." Period Polytech-Chem 61 (2017): 73-81.

8. Heins, W.F. "Is a Paradigm Shift in Produced Water Treatment Technology Occurring at SAGD Facilities?" J Can Pet Technol 49 (2010): 10-15.

9. Liu, Shumeng, Zhao, Xuefeng, Dong, Xigui, Miao, Baolin, and Wei Du. "Experimental Research on Treatment of Produced Water from a Polymer-Flooding Process Using a Double-Cone Air-Sparged Hydrocyclone." SPE Proj Fac \& Const 2 (2007): $1-5$.

10. Liu, Shumeng, Zhang, Zhenjia, Dong, Xigui, Zhao, Xuefeng, and Wei Du. "Treatment of ASP Produced Water with Hydrophilic Fibre Ball Filtration." Paper presented at the The Fifteenth International Offshore and Polar Engineering Conference, Seoul, Korea, June 2005.

11. Kenawy, F.A., Kandil, M.E., Fouad, M.A., and T.W. Aboarab. "Produced Water Treatment Technology, A Study of Oil/Water Separation in Gravity Type Cross Flow Pack Separators for Qualitative Separation." SPE Prod \& Fac 12 (1997): 112-115. 